\title{
AN UNUSUAL MONTMORILLONITE COMPLEX
}

By R. Greene-Kelly

Rothamsted Experimental Station, Harpenden, Herts.

[Read 5th November, 1954]

ABSTraCT

Sodium montmorillonite and pyridine form a regular complex of spacing $23.3 \mathrm{kX}$ in the presence of traces of moisture. The minimum interlamellar composition necessary for the formation of the complex is approximately $\mathrm{Na}+\left(\mathrm{C}_{5} \mathrm{H}_{5} \mathrm{~N}\right)_{4}\left(\mathrm{H}_{2} \mathrm{O}\right)_{2}$. The intensities of the $00 l$ reflections are considered incompatible with the complex having a five layer structure and an alternative arrangement is proposed.

\section{INTRODUCTION}

Bradley (1945) first noticed that the $14.8 \mathrm{kX}$ complex of pyridine and montmorillonite was replaced by one of increased spacing when excess pyridine was present. This paper describes some work done on this higher spacing complex.

\section{Experimental Procedure}

To determine the amount of pyridine necessary for the formation of the complex, adsorption measurements were carried out from solutions of pyridine in dekalin on to sodium montmorillonite dried at $100^{\circ} \mathrm{C}$. The concentration changes were determined by shaking an aliquot of the solution with excess acid and back-titrating with alkali using screened methyl orange as indicator. X-ray powder photographs were taken of the montmorillonite samples after adsorption to determine the point at which the high spacing complex was formed.

More detailed X-ray work was carried out on sodium montmorillonite flakes; by turning the flakes to make various angles with the $\mathrm{X}$-ray beam up to twenty $00 l$ reflections could be observed with $\mathrm{Cu} \mathrm{Ka}$ radiation and within experimental error this $00 \mathrm{l}$ sequence appeared to be rational. The intensities of the reflections were recorded using the multiple film technique and were both visually and photometrically estimated. After making corrections for absorption, Lorentz, polarisation and preferred orientation effects the intensities were converted to structure factors. No attempt was made to apply temperature factors since the resultant structure factors formed only a short sequence and the application of a temperature factor tended to produce spurious effects without materially improving the resolution of the one dimensional Fourier sketch. The structure factors were compared with those calculated for the silicate sheets alone (assuming the muscovite structure) and the signs allocated on the assumption that the silicate sheet structure factors preponderated. A preliminary one dimensional Fourier synthesis was carried out and the resultant sketch was used as a basis for cal- 
culating the new signs. The process was repeated until no further sign changes occurred.

\section{RESULTS}

Preliminary spacing measurements of the saturated pyridinesodium montmorillonite complex showed that the complex was regular and possessed a spacing of $23.3 \mathrm{kX}$. It was found that unheated lithium montmorillonite also produced the complex but montmorillonites saturated with divalent cations produced only. a

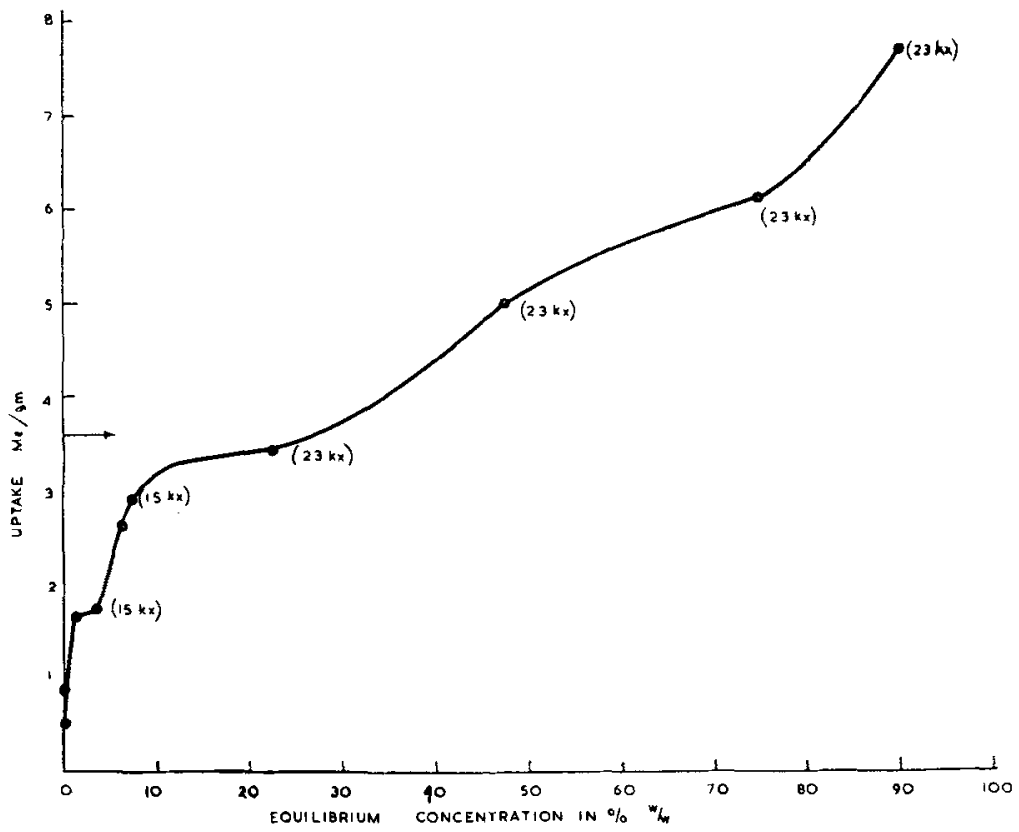

Frg. 1-Adsorption of pyridine by sodium montmorillonite from decalin solutions.

weak $23 \mathrm{kX}$ reflection, the $00 /$ reflections corresponding to the $14.8 \mathrm{kX}$ complex predominating. Potassium montmorillonite formed the $23 \mathrm{kX}$ complex with considerable random interstratification, its behaviour being similar to that with most other organic liquids. Pyridinium montmorillonite did not form the $23 \mathrm{kX}$ complex.

If both montmorillonite and pyridine were carefully dried the $23 \mathrm{kX}$ complex could not be prepared. If the complex was first formed in the presence of moisture, it was found to be destroyed if the pyridine in contact with the montmorillonite was dried by refluxing in a soxhlet extractor with the drying agent in the extraction chamber. It was estimated that about $40 \mathrm{mg}$. water per g. clay was required to stabilise the complex. 
The adsorption measurements were carried out in the presence of traces of moisture and the results were calculated on the assumption that there was no solvent sorption. (See Greene-Kelly 1955b for a discussion of the basis for this assumption). The results are given in Figure 1. It is seen that between $1.8 \mathrm{me} / \mathrm{g}$. and $3.5 \mathrm{me} / \mathrm{g}$. the $15 \mathrm{kX}$ complex was stable but above $3.5 \mathrm{me} / \mathrm{g}$. the $23 \mathrm{kX}$ complex was formed.

The results of the one dimensional fourier synthesis using the intensities of $00 l$ reflections given in Table 1 are shown in Figure 2.

TABLE 1-Structure factors of $00 l$ reflections of the saturated pyridinesodium montmorillonite complex.

\begin{tabular}{|rrrrr|rrrrr}
\hline $00 l$ & $F_{\exp }$ & $F_{s}$ & $F_{1}$ & $F_{2}$ & $00 l$ & $F_{\exp }$ & $F_{s}$ & $F_{1}$ & $F_{2}$ \\
\hline 1 & 76 & 145 & 97 & 91 & 11 & 28 & $\overline{37}$ & $\overline{26}$ & $\overline{39}$ \\
2 & 44 & $\frac{64}{52}$ & 52 & 94 & 12 & 26 & $\overline{40}$ & $\overline{40}$ & $\overline{42}$ \\
3 & 16 & $\overline{14}$ & $\overline{2}$ & $\frac{4}{13}$ & 13 & 26 & $\overline{24}$ & $\overline{2}$ & $\overline{28}$ \\
4 & 24 & $\overline{44}$ & 1 & $\overline{37}$ & 14 & 10 & 3 & 0 & 15 \\
5 & 46 & $\overline{23}$ & $\overline{27}$ & 45 & 15 & 12 & 26 & 33 & 10 \\
6 & 40 & 24 & 8 & 50 & 16 & 20 & 39 & 54 & 47 \\
7 & 30 & 58 & 52 & 47 & 17 & 22 & 43 & 10 & 39 \\
8 & 58 & 59 & 105 & 82 & 18 & 18 & 36 & 56 & 34 \\
9 & 10 & 29 & $\overline{13}$ & $\overline{1}$ & 19 & 18 & 25 & 16 & 26 \\
10 & 12 & $\overline{10}$ & $\overline{1}$ & $\overline{1}$ & 20 & 8 & 13 & 9 & 27 \\
\hline
\end{tabular}

Fexp-Structure factors obtained from the observed intensities after correction for orientation, absorption, Lorentz and polarisation effects. $F_{s}-$ Calculated structure factors for the silicate sheet only. $F_{1}-$ Calculated structure factors for a five layer complex. Layers each of $36 \mathrm{e}$ per unit cell area at 16, 23, 30, 37, 44 sixtieths of $c . \quad F_{2}-$ Calculated structure factors for the proposed configuration. Electron density per unit cell area of $12 \mathrm{e}$ assumed at 16, 24, 36, 44; $24 \mathrm{e}$ at $18,22,38,42$ and $48 \mathrm{e}$ at 30 sixtieths of $c$.

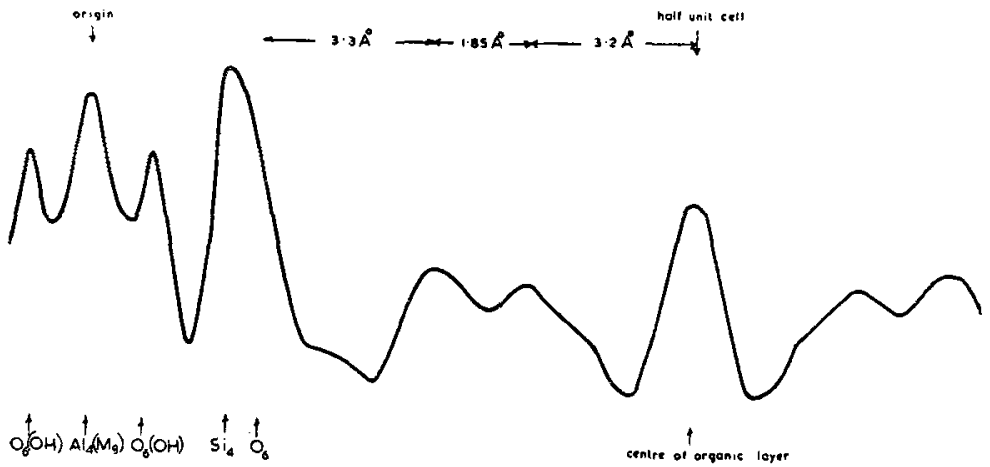

(5.8) (4ag) (56) (4a8)

FIG. 2-One dimensional fourier synthesis perpendicular to the plane of the silicate sheet. 
It is seen that the silicate sheet is fairly well resolved, the most notable feature of the organic layer being the pronounced peak at a point midway between the silicate sheets.

An attempt to prepare the $23 \mathrm{kX}$ complex with either 2 or 4 methyl pyridine showed that the former compound gave a spacing of $22 \mathrm{kX}$ but the latter did not give a spacing greater than $15 \mathrm{kX}$. Collidine $(2,4,6)$ did not form a high spacing complex and neither did quinoline. Isoquinoline showed a tendency to give a weak reflection near $30 \mathrm{kX}$ but it was not possible to investigate this in detail owing to lack of orders in the X-ray photographs.

\section{Discussion}

The conditions of formation of the $23 \mathrm{kX}$ complex suggest that it is a mixed complex of pyridine and water with a minimum composition, expressed in terms of molecules per sodium ion, of $\left(\mathrm{C}_{5} \mathrm{H}_{5} \mathrm{~N}\right)_{4}\left(\mathrm{H}_{2} \mathrm{O}\right)_{2}$. The composition can almost certainly increase with respect to pyridine and possibly also with respect to water, but it seems clear that the minimum composition represents the structural unit which is responsible for the formation of the complex, other molecules merely being inserted between the structural units until close packing is achieved. The formation of the complex appears to be inhibited by the presence of divalent cations and whilst there is no simple explanation of this effect it does suggest that the cations play an important part in the structure of the complex.

The electron density sketch shown in Figure 2 shows a pronounced peak midway between the silicate sheets and this is interpreted as being due to a coplanar arrangement of molecules. The electron density sketch roughly resembles that of a five layered arrangement with the central layer being more pronounced. There are however a number of difficulties to this conclusion. There are no intermediate pyridine complexes of two, three or four layers; two of the former peaks are too near to one another; and the total amount of space available to a five layer arrangement is such that the contact distances between molecules would be smaller than expected on the basis of either the study of the simple aromatic complexes (Greene-Kelly 1955a) or the results obtained from studies of crystals of aromatic compounds. The observed intensities are also considered incompatible with a five layer complex as inspection of table 1 will show. On general grounds, the preoccupation with the presence of layered arrangements in montmorillonite complexes does seem to stem more from theoretical surface chemical considerations than experimental facts. There is no evidence that either two, three or four layer arrangements are ever formed with aromatic compounds and it is even doubtful whether other cases reported (e.g., aliphatic complexes, MacEwan 1948) would bear close examination. If the five layered structure is rejected the number of interpenetrating arrangements become too numerous to be distinguished by a one-dimensional synthesis, however satisfactory, and the postulation of a structure can hardly be anything else but speculative. A suggested arrangement is 
shown in Figure 3 where the essential unit of structure is regarded as $\mathrm{M}+\left(\mathrm{C}_{5} \mathrm{H}_{5} \mathrm{M}\right)_{4}\left(\mathrm{H}_{2} \mathrm{O}\right)_{2}$ where $\mathrm{M}$ is a $\mathrm{Li}^{+}$or $\mathrm{Na}^{+}$. It is seen that the planar arrangement of two water and two pyridine molecules is supported by pyridine molecules oriented perpendicular to the silicate sheets. Between such pillars there is room for the accom-

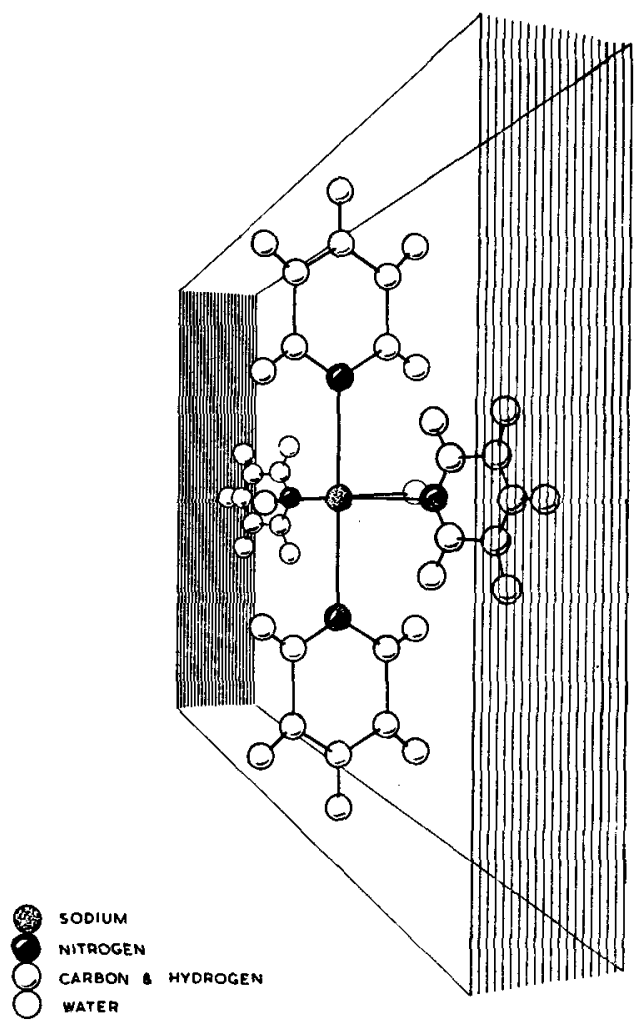

SILICATE SHEET

FIG. 3- Suggested structure of the pyridine-sodjum montmorillonite complex.

modation of more pyridine with no increase of spacing in agreement with the adsorption results.

\section{REFERENCES}

Bradley, W. F. 1945 J. Am. Chem. Soc., 67, p. 975.

Greene-Kelly, R. 1955a Trans. Farad. Soc., 51, p. 412.

1955 b Ibid., 51, p. 425.

MacEwan, D. M. C. 1948 Ibid., 44, p. 349. 
Discussion

Dr G. Nagelschmidt said that while the structure proposed seemed attractive there wcre two difficulties to its acceptance. (1) The different co-ordination of the lithium structure (presumably 6) and (2) the presence of four methyl groups around the sodium in the picolines. He also asked if it was possible to introduce other material, e.g., picoline into the excess space after the "columns" had been built.

Dr I. Havenaar recalled that the author had, as a possible explanation of the absence of adsorption of pyridine on clays containing divalent cations in the layers, postulated that the number of ions was too small-half as small as when for example $\mathrm{Na}$ ions were present-to support the structure. Havenaar continued and pointed out that with the $\mathrm{K}^{+}$ion the adsorption was only $50 \%$ of that observed with other monovalent ions. This would indicate that there was at least one other factor preventing adsorption of pyridine and asked if the author had any opinion about this factor.

Dr B.S. Neumann said that even with divalent ions such as $\mathrm{Ca}$ some regions of stability might be effected and asked if this occurred.

$\mathrm{Mr} R$. H. Robertson asked if there was any development of colour in the complexes.

Dr R. Greene-Kelly in reply said that the formation of the complex with lithium montmorillonite and with picoline would suggest that the number of molecules co-ordinated round the cations was less than six. Although the arrangement illustrated in Figure 3 showed the sodium ions as six co-ordinated, this was intended to emphasise the importance of the cations in the complex rather than to give a precise number to their co-ordination. There was, of course, no evidence of where the cations were situated or how they were co-ordinated.

There was an increasing amount of evidence pointing to the heterogenous nature of many montmorillonites. (See Greene-Kelly 1955). There might be for example, differences in composition between silicate sheets joined together in the same crystallite, leading to a non-uniform expansion of the mineral. This might be the reason why potassium montmorillonite (Wyoming bentonite) usually gave an irrational series of $00 \mathrm{l}$ reflections when saturated in glycerol and other organic compounds and why calcium montmorillonite formed a trace of the $23 \mathrm{kX}$ complex as well as the $15 \mathrm{kX}$ complex in pyridine.

In reply to $\mathrm{Mr}$ Robertson, the author said that the pyridine complex was coloured blue if analar pyridine was used but with pyridine from other sources this colour did not appear. It was well known that many aromatic amines gave green and blue colours with ironbearing montmorillonites, the most spectacular case being that of dimethylaniline which colours montmorillonites left open to the laboratory atmosphere if a bottle of the unopened amine is standing nearby. The sensitivity of the reaction was such that the colours with pyridine were more likely to be due to a slight impurity in the 
sample than to pyridine itself. In passing it was interesting to note that the colour was not formed unless the montmorillonite had been previously dried and that heating, as might be expected, accelerated the colouring process. It might be thought that the colouring action was connected with interlamellar sorption but in the case of dimethylaniline which was only sorbed slowly and with difficulty, the colouring action was particularly intense and was completed before X-ray photographs showed much interlamellar penetration. The phenomenon therefore appeared to be connected with the external surfaces (broken bond surfaces?).

\section{REFERENCE}

Greene-Kelly, R. 1955 Min. Mag,, 31, 604. 